\title{
Spontaneous Growth in Growth Hormone-Treated Short Children
}

\author{
Toshiaki TANAKA, KazUe TAKANO, KuniHIKo HANEW, YoshiKazU NISHI, KenjI FUJIEDA, \\ KATSUHIKO TACHIBANA, SUSUMU YOKOYA, YUTAKA IGARASHI, AND TAKEKI HIRANO
}

Study Group of GH Treatment, Foundation for Growth Science, Tokyo, Japan

IT IS reported that special GH or GH receptor disorders, such as Laron syndrome and GH deficiency type I, show severe growth retardation. However, natural growth pattern of idiopathic GH deficiency (GHD) have not yet reported in Japan.

The aim of this study was to investigate the characteristics of pretreatment height profile in GH-treated short children cross-sectionally registered to the Foundation for Growth Science.

\section{Subjects and Method}

Thirteen thousand and seven hundred forty-three short children (9,564 boys and 4,178 girls) of idiopathic origin were evaluated for indication of GH treatment according to the criteria of the Foundation for Growth Science up to 1992 and were reported to have started GH treatment.

These patients were classified into three groups according to $\mathrm{GH}$ secretion capacity: those with complete GHD (CGHD) whose maximum peak GH level in stimulation tests was less than $5 \mathrm{ng} / \mathrm{ml}$, those with non-endocrine short stature (NESS) whose maximum peak $\mathrm{GH}$ level was more than 10 $\mathrm{ng} / \mathrm{ml}$, and the remaining patients defined as having partial GHD (PGHD).

Median height SDS was calculated at each age in three groups and the difference among groups was estimated by Kruskal-Wallis test.

Correspondence to: Dr. Toshiaki TANAKA, National Children's Medical Research Center, 3-35-31 Taishi-do, Setagaya-ku, Tokyo 154, Japan

Key words: GH deficiency (GHD), GH treatment, Final height

\section{Results}

A ratio of boys to girls was approximately 2 to 1 and percentages of CGHD, PGHD and NESS were $16.4 \%, 48.0 \%$ and $35.6 \%$ in boys and $16.0 \%, 48.3 \%$ and $35.7 \%$ in girls, respectively.

Median height SDS at the start of GH treatment was $-2.61 \mathrm{SD}$ in boys and $-2.79 \mathrm{SD}$ in girls. Height SDS at the start of GH treatment was significantly smaller in CGHD than the others (Table 1). Height SDS in CGHD was significantly smaller than the others before 12 years in boys and before 8 years in girls, and there was no significant difference in height SDS between PGHD and NESS (Fig. $1(\mathrm{a})(\mathrm{b})$ ). Height SDS at the start of GH treatment over 17 years in boys and over 15 years in girls was approximately -4 SD as shown in Table 2.

\section{Discussion}

We have already shown that CGHD was significantly different from PGHD and NESS in clinical characteristics and response to $\mathrm{GH}$ treatment but

Table 1. Height SDS at start of GH treatment

\begin{tabular}{lcccc}
\hline & \multicolumn{2}{c}{ Male } & \multicolumn{2}{c}{ Female } \\
& $\mathrm{N}$ & SDS & $\mathrm{N}$ & SDS \\
\hline \multirow{2}{*}{ ALL } & \multirow{2}{*}{9564} & -2.61 & 4178 & -2.79 \\
\hline CGHD & 1570 & -2.86 & 671 & -3.06 \\
PGHD & 4592 & -2.57 & 2017 & -2.77 \\
NESS & 3402 & -2.57 & 1490 & -2.73 \\
\hline
\end{tabular}

CGHD, complete GH deficiency; PGHD, partial GHD; NESS, non-endocrine short stature. 
(a)

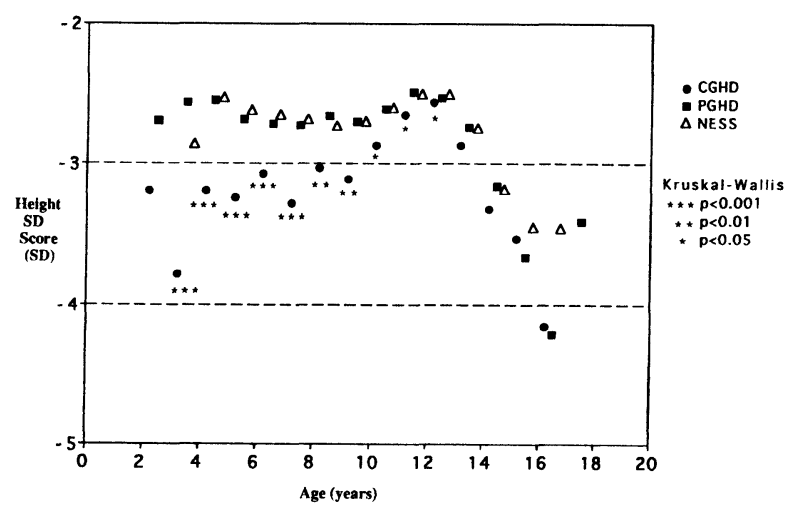

(b)

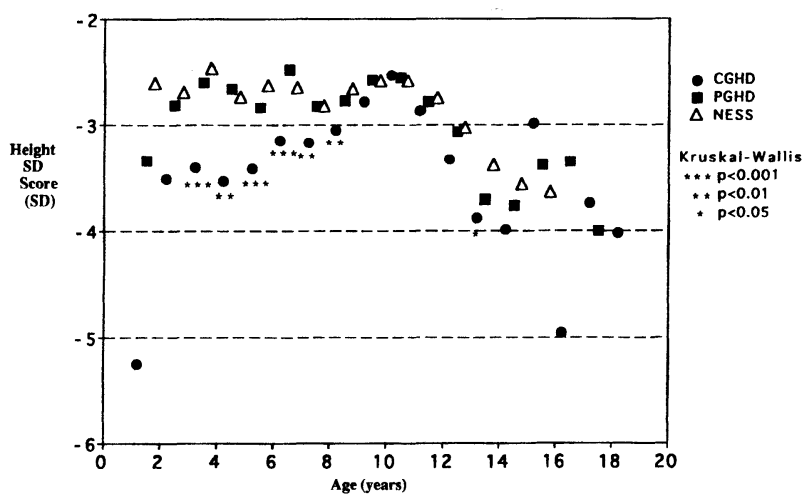

Fig. 1. Median height SDS at the start of GH treatment in patients with CGHD (O), PGHD $(\square)$ and NESS ( $\triangle$ ). (a) boys, (b) girls.

Table 2. Median height and height SDS in male patients over 17 years and in female patients over 15 years who started GH treatment

\begin{tabular}{lccc}
\hline & $\mathrm{N}$ & $\begin{array}{c}\text { Height } \\
(\text { 10th 90th centiles })\end{array}$ & $\begin{array}{c}\text { Height SDS } \\
\text { (10th 90th centiles) }\end{array}$ \\
\hline Male & 29 & $146.1(123.2 \sim 158.0)$ & $-4.33(-8.42 \sim-2.22)$ \\
Female & 26 & $138.3(128.6 \sim 146.0)$ & $-3.90(-5.67 \sim-2.29)$ \\
\hline
\end{tabular}

there was no significant difference between PGHD and NESS [1]. This study also showed the same results in height at the start of GH treatment, but there was no difference among the three groups in height SDS at the start of GH treatment after pu- bertal age in boys and girls. The reason why there was no significant difference may be that severe cases had already been diagnosed before puberty. The fact that higher percentage of CGHD in early childhood supports the above mentioned hypothesis. Approximately two thirds of CGHD had already been treated before puberty.

Ninety percent of boys over 17 years and ninety-six percent of girls over 15 years were GHD. Therefore, adult height in GHD patients without treatment is speculated to be approximately -4 SD, but the adult height SDS may be overestimated since severe cases had been treated in early childhood.

\section{Reference}

1. Tanaka T (1991) Growth hormone secretion and the therapeutic effects of human growth hormone:
First Japanese results of KIGS/ICGS. Acta Paediatr Scand (suppl) 379: 126-135. 